\title{
Relato da ocorrência simultânea de escrofuloderma, eritema indurado de Bazin e tuberculide pápulo-necrótica em paciente imunocompetente
}

\author{
Report of simultaneous occurrence of scrofuloderma, Bazin's indurated erythema \\ and papulonecrotic tuberculid on an immunocompetent patient.
}

Helena Reich Camasmie ${ }^{1}$, Ricardo Barbosa Lima ${ }^{1}$, Fernanda Costa de Aguiar ${ }^{1}$, Luiza Peres Barbosa ${ }^{1}$, Luciana Ferreira de Araújo ${ }^{1}$, Carlos José Martins ${ }^{1}$

\begin{abstract}
RESUMO
Modelo do estudo: relato de caso

I mportância do problema: A tuberculose é um grave problema de saúde no nosso país, no entanto poucos profissionais sabem identificar as formas extrapulmonares da doença, que são responsáveis por 23,3\% dos óbitos por tuberculose no Brasil. Das formas extra-pulmonares, apenas 1-2\% representam formas cutâneas. É importante que o médico generalista conheça as formas cutâneas de tuberculose, uma vez que pode ser a única manifestação da doença. O seu diagnóstico é um desafio, pois os exames tradicionais têm menor sensibilidade e especificidade para a apresentação cutânea em relação à forma pulmonar. No entanto, novos exames vêm sendo implantados como o GeneXpert.

Comentários: Relatamos um caso raro de tuberculose cutânea em paciente imunocompetente, com a manifestação de três formas clínicas simultaneamente - escrofuloderma, tubercúlide papulonecrótica e eritema indurado de Bazin. A ocorrência de duas formas simultâneas é descrita na literatura mas a ocorrência de três formas simultâneas é inédita. Essa manifestação atípica foi de difícil diagnóstico clínico por simular outras doenças e os exames tradicionais como o RX de tórax, baciloscopia e cultura não evidenciaram o diagnóstico. A identificação do Mycobacterium tuberculosis só foi possível por meio da pesquisa de PCR com o GeneXpert, que mostrou positividade no escarro pulmonar e no exsudato do escrofuloderma, possibilitando iniciar o tratamento precocemente. Este novo exame de alta sensibilidade e especificidade no diagnóstico da tuberculose pulmonar mostrou-se de grande utilidade no diagnóstico deste caso atípico de tuberculose cutânea onde os exames tradicionais não definiram o diagnóstico.
\end{abstract}

Palavras-chave: Mycobacterium tuberculosis. Tuberculose. Tuberculose Cutânea. Eritema Endurado. Diagnóstico. Reação em Cadeia da Polimerase.

CORRESPONDÊNCIA: Helena Reich Camasmie Rua Thales de Aquino Coelho, 160 CEP 22793-300 - Rio de Janeiro/RJ - Brazil helena@camasmie.com

Recebido em 21/05/2018 Aprovado em 24/10/2018 


\begin{abstract}
Study: Case Report

I mportance: Tuberculosis is a serious health problem in Brazil. Nevertheless, only few physicians know how to identify the non-pulmonary cases of this disease, which can represent up to $23,3 \%$ of deaths caused by tuberculosis in Brazil. Among the non-pulmonary cases, only 1-2\% affect the skin. It is important for the general physician to understand the cutaneous presentations of tuberculosis, once it can be the only symptom that the patient presents. Diagnosing cutaneous tuberculosis is a challenge, because traditional laboratory tests have smaller sensitivity and specificity for the cutaneous form in contrast to pulmonary tuberculosis. However, implementation of new exams such as GeneXpert may come in hand.

Comments: We report a rare case of cutaneous tuberculosis on an immunocompetent patient, with three different simultaneous presentations - scrofuloderma, papulonecrotic tuberculids and Bazin's indurated erythema. Occurrence of two simultaneous presentations has been reported, however, three simultaneous forms have not. Diagnosing this atypical manifestation was very hard because the clinical presentation often mimics other dermatological conditions, and traditional laboratory testing such as chest X-ray, bacilloscopy and culture did not evidence infection. Identification of Mycobacterium tuberculosis was only possible due to positive PCR testing through GeneXpert on pulmonary and scrofuloderma fluids, allowing rapid treatment initiation. This new high sensitivity and specificity exam proved to be of great value when diagnosing this atypical cutaneous tuberculosis case, in which diagnose was not possible through traditional laboratory testing.
\end{abstract}

keywords: Mycobacterium tuberculosis. Tuberculosis. Tuberculosis, Cutaneous. Erythema Induratum. Diagnosis. Polymerase Chain Reaction.

\section{INTRODUÇÃO}

O Brasil ocupa a 20 a posição na lista de países com alta carga de tuberculose. Em 2017 foram notificados 72.770 casos novos, com 33.769 casos concentrados na região Sudeste, correspondendo a aproximadamente metade da incidência de novos casos no país. Esse número corresponde a um coeficiente de incidência de 35 casos/100mil habitantes, com um coeficiente de mortalidade igual a 2,2 óbitos/100mil habitantes. ${ }^{1} \mathrm{Em}$ geral, $13,5 \%$ são formas extra-pulmonares, que são responsáveis por $23,3 \%$ dos óbitos por tuberculose no Brasil. ${ }^{2}$ Das formas extra-pulmonares, apenas 1-2\% representam formas cutâneas. ${ }^{3}$

A tuberculose cutânea (TC) é classificada em várias formas clínicas, que variam de acordo com a exposição prévia ao bacilo, o estado imunológico do hospedeiro e a via de infecção. O seu diagnóstico é um desafio, pois os métodos diagnósticos tradicionais apresentam menor sensibilidade e especificidade para a apresentação cutânea em relação à forma pulmonar. ${ }^{4}$ No entanto, novos exames vêm sendo desenvolvidos. Relatamos um caso de TC em paci- ente imunocompetente, com três formas clínicas simultâneas, no qual o teste GeneXpert foi o exame definidor do diagnóstico.

\section{RELATO DE CASO}

Paciente do sexo feminino, 16 anos, referindo início do quadro com nódulos nas panturrilhas com ulceração central. Posteriormente, surgiram pápulas nos membros superiores, dorso e abdômen. Fez uso de cefalexina com regressão do quadro, porém há seis meses ocorreu recidiva das lesões em maior número e maior tamanho. Negava história pregressa de tuberculose ou contato com portadores da doença. A paciente era de baixo nível sócio-econômico e habitava em ambiente com condições sanitárias precárias, no entanto, apresentava-se em bom estado geral e sem sinais clínicos de desnutrição. Não apresentava queixas respiratórias ou outros sintomas.

Ao exame dermatológico, apresentava nas panturrilhas lesões nodulares, algumas ulceradas, com bordas irregulares e fundo eritemato-amarelado (Figura 1). Além destas lesões, notava-se nos 


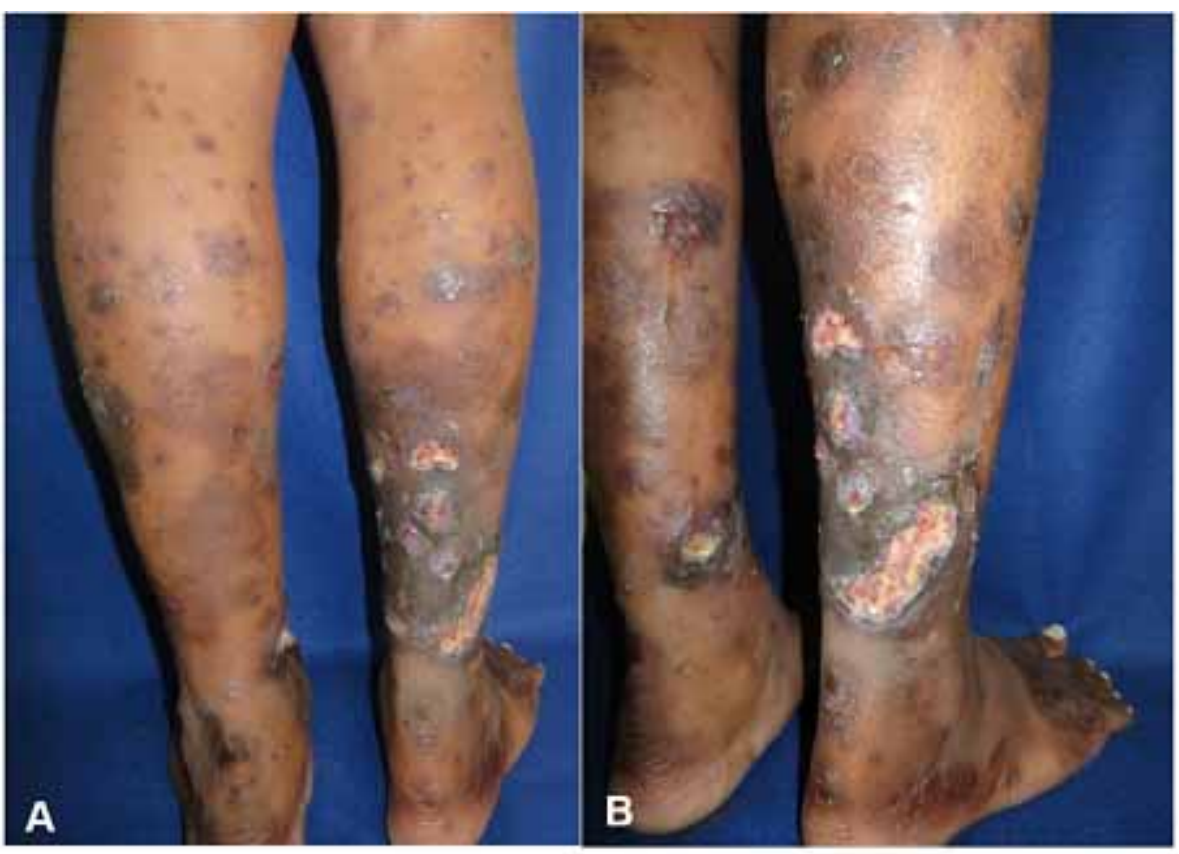

Figura 1: A-B: nas panturrilhas, lesões nodulares, algumas ulceradas, com bordas irregulares e fundo eritemato-amarelado compatíveis com eritema indurado de Bazin.

membros inferiores, membros superiores, abdômen e dorso, pápulas, ora eritematosas, ora hipercrômicas, algumas com centro necrótico, e outras com umbilicação central (Figuras 2-3). $\mathrm{Na}$ região submentoniana apresentava lesão nodular eritematosa de superfície ulcerada, drenando exsudato purulento. (Figura 4) As principais hipóteses foram uma infecção bacteriana, sendo as úlceras dos membros inferiores sugestivas de ectima, a lesão da região submentoniana sugestiva de um abcesso e as pápulas disseminadas sugestivas de um prurigo por picada de inseto com infecção secundária superposta. Além destas hipóteses foram aventadas também as hipóteses de pioderma gangrenoso, infecções fúngicas (criptococose e histoplasmose) e tuberculose cutânea, no entanto o polimorfismo lesional dificultava considerar todas as lesões dentro de um mesmo diagnóstico etiológico. Foram realizadas biópsias de duas lesões. Uma na panturrilha, onde a amostra não incluiu o tecido subcutâneo, evidenciando apenas alterações inespecíficas. Outra, em lesão papulosa no braço, em que o exame microscópico revelou lesão ulcerada recoberta por material necrótico. $\mathrm{Na}$ derme, notava-se processo inflamatório granulomatoso, configurando aspecto em " $\mathrm{V}$ ", com áreas de necrose (Figura 5). Colorações especiais não evidenciaram microrganismos. Dentre os exames complementares, destacamos a pesquisa de BAAR no escarro e cultura para M. tuberculosis negativos, Raio-X de tórax sem alterações e sorologia para HIV negativa. O PPD não estava disponível. Foi realizado o teste GeneXpert do escarro pulmonar e do exsudato purulento ganglionar que foram positivos para M. tuberculosis. De acordo com esses achados concluímos tratar-se de TC. Foi introduzido esquema RIPE com cicatrização das lesões (Figuras 6-7).

\section{DISCUSSÃO}

No caso relatado, de acordo com o nível sócio econômico da paciente, habitando em ambiente com condições sanitárias precárias, com história de melhora anterior com uso de antibióticos orais, a etiologia mais comum seriam as infecções bacterianas da pele. No entanto diante do quadro clínico exuberante foram consideradas outras hipóteses, entre elas a tuberculose cutânea que foi confirmada através dos exames realizados.

A TC pode ser dividida em dois grandes grupos: as tuberculoses e as tubercúlides (Quadro $1)^{5}$. A apresentação clínica da TC irá depender de 


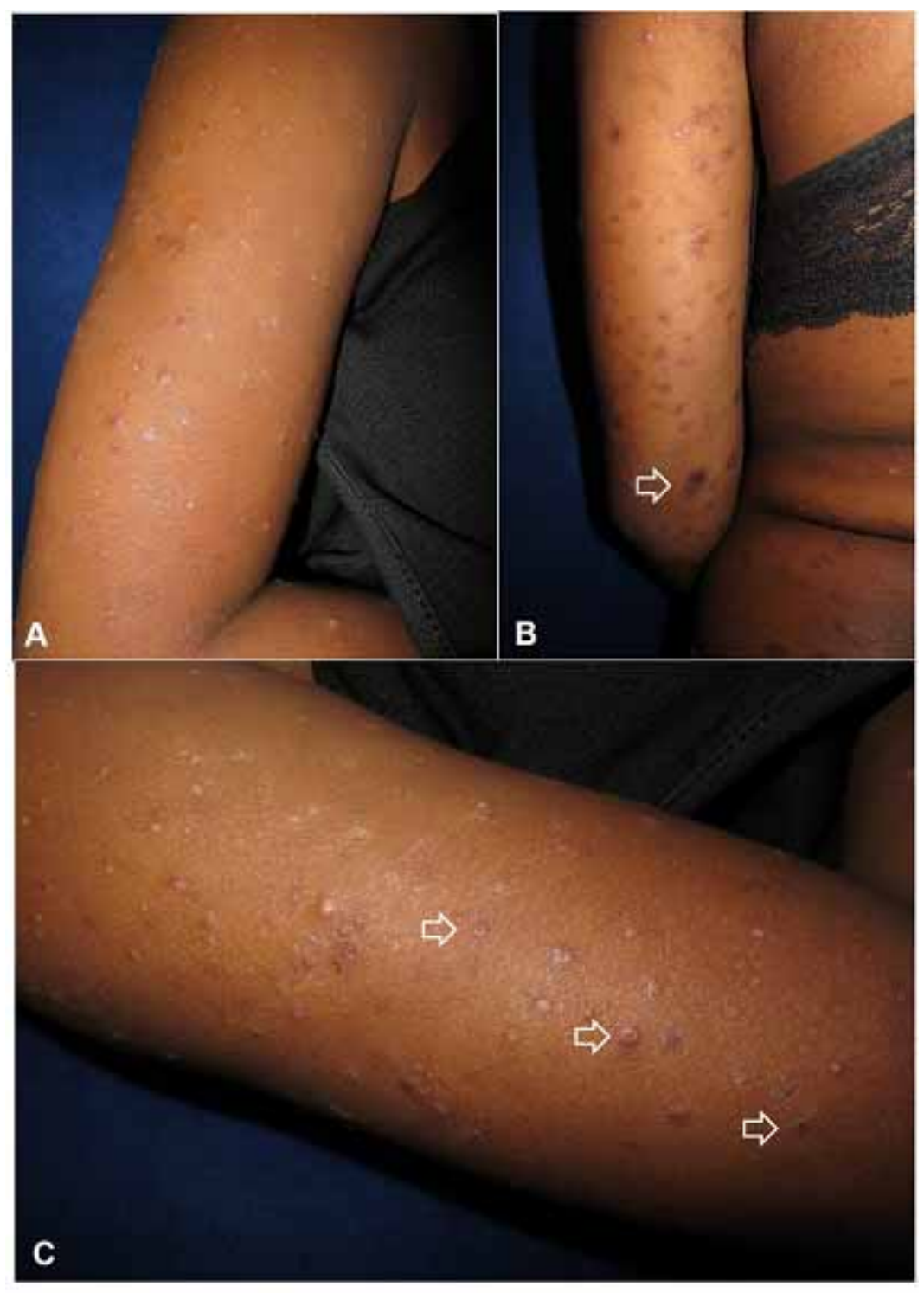

Figura 2: A) nos membros superiores pápulas, ora eritematosas, ora hipercrômicas B) algumas com centro necrótico (seta) C) outras com umbilicação central (seta), compatíveis com tubercúlide pápulo-necrótica.

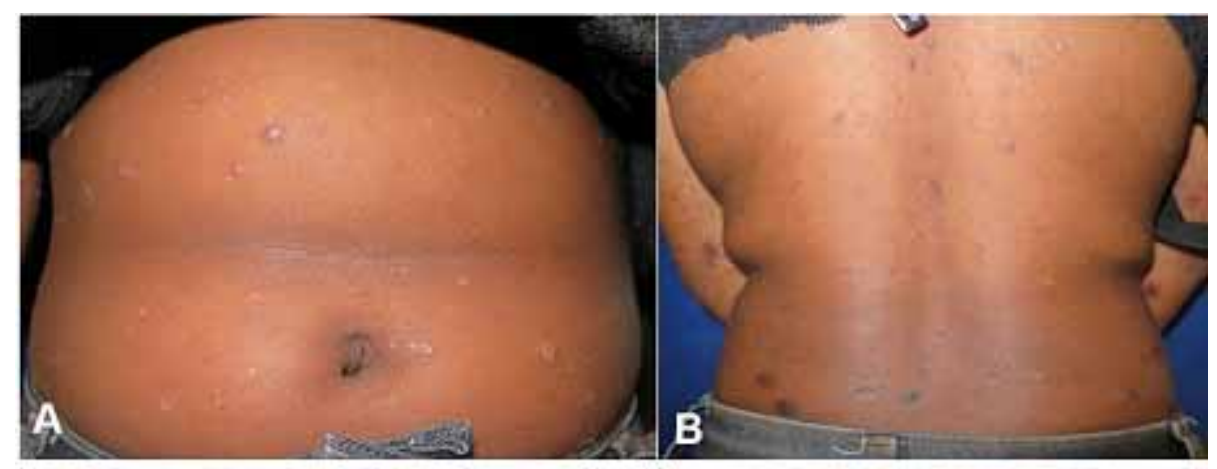

Figura 3: A) pápulas no abdome e B) no dorso. 


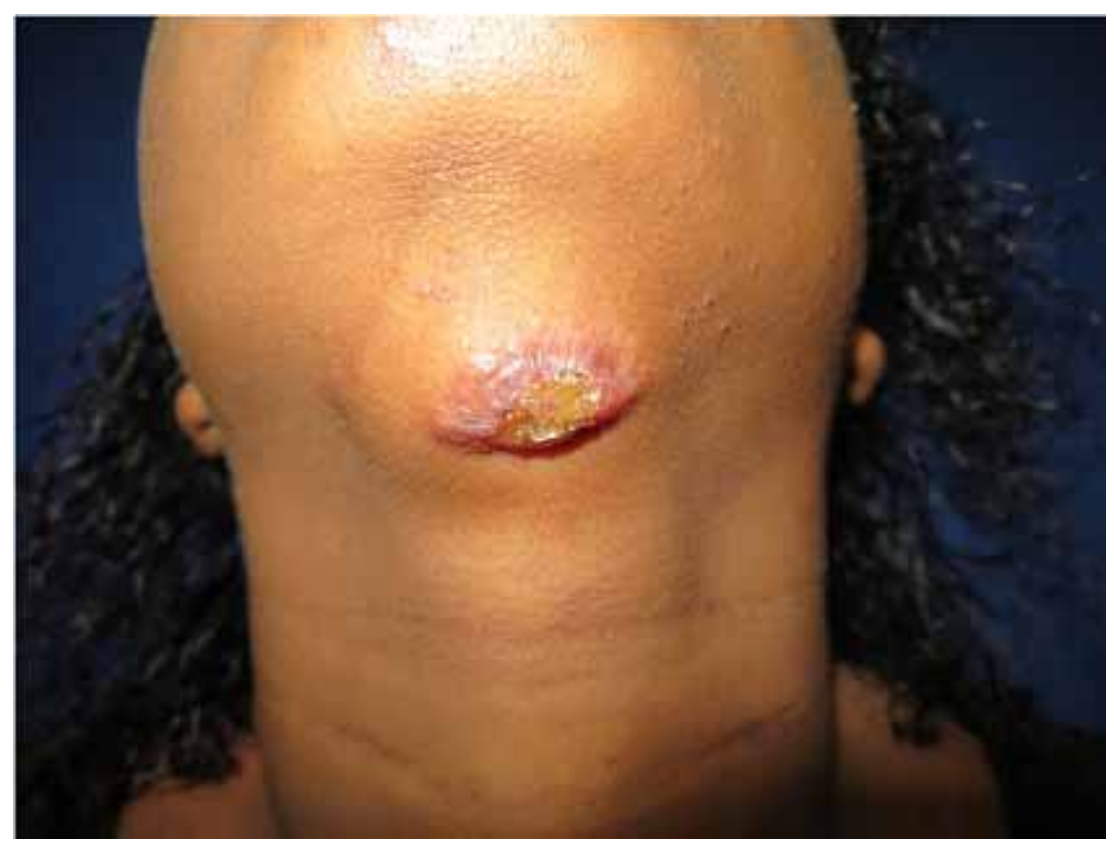

Figura 4: Na região submentoniana, lesão nodular eritematosa de superfície ulcerada, drenando exsudato purulento, compatível com escrofuloderma.

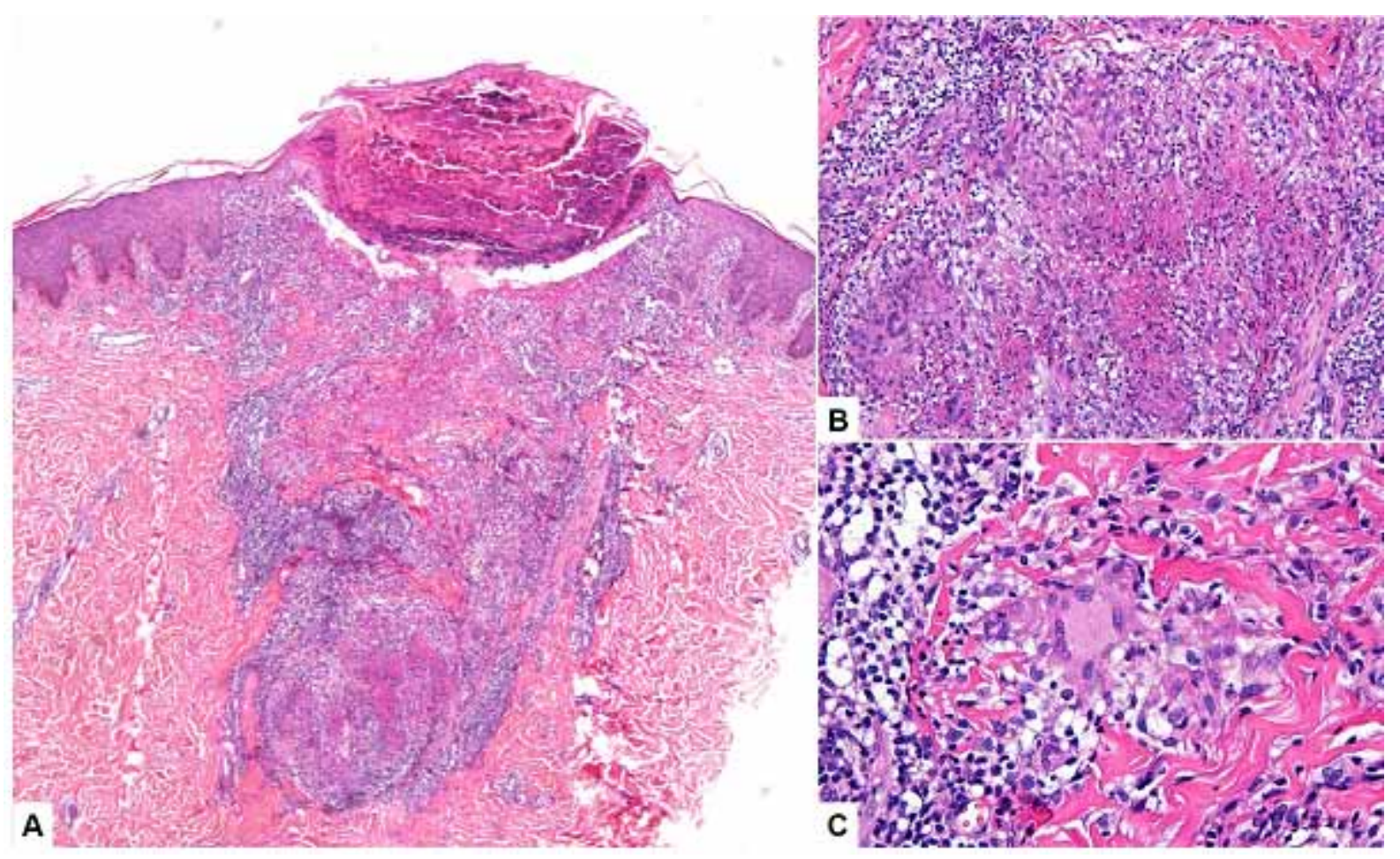

Figura 5: A) Exame microscópico de pápula do braço mostrando lesão ulcerada recoberta por material necrótico. Na derme, processo inflamatório granulomatoso, configurando aspecto em "V" (HE 40x) B) infiltrado inflamatório constituído por linfócitos, células epitelióides, células gigantes tipo Langhans e áreas de necrose (HE 200x) C) célula gigante do tipo Langhans em meio ao infiltrado inflamatório (HE400x). 


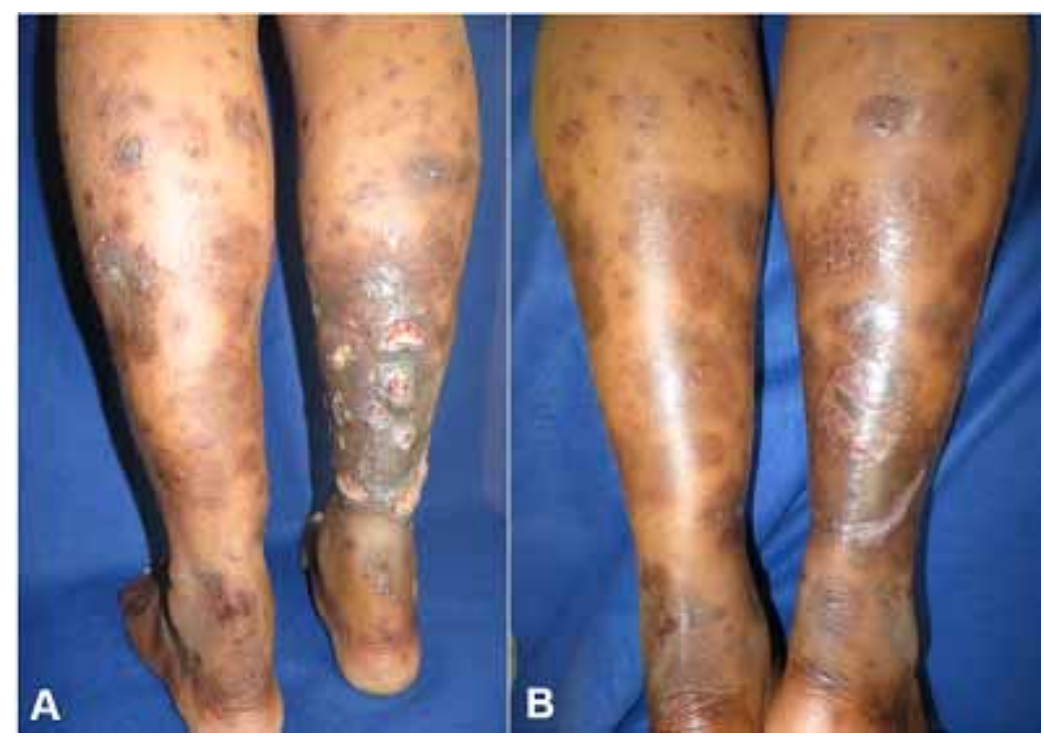

Figura 6: A) lesões das panturrilhas antes e B) no $3^{\circ}$ mês do esquema RIPE com cicatrização das lesões.

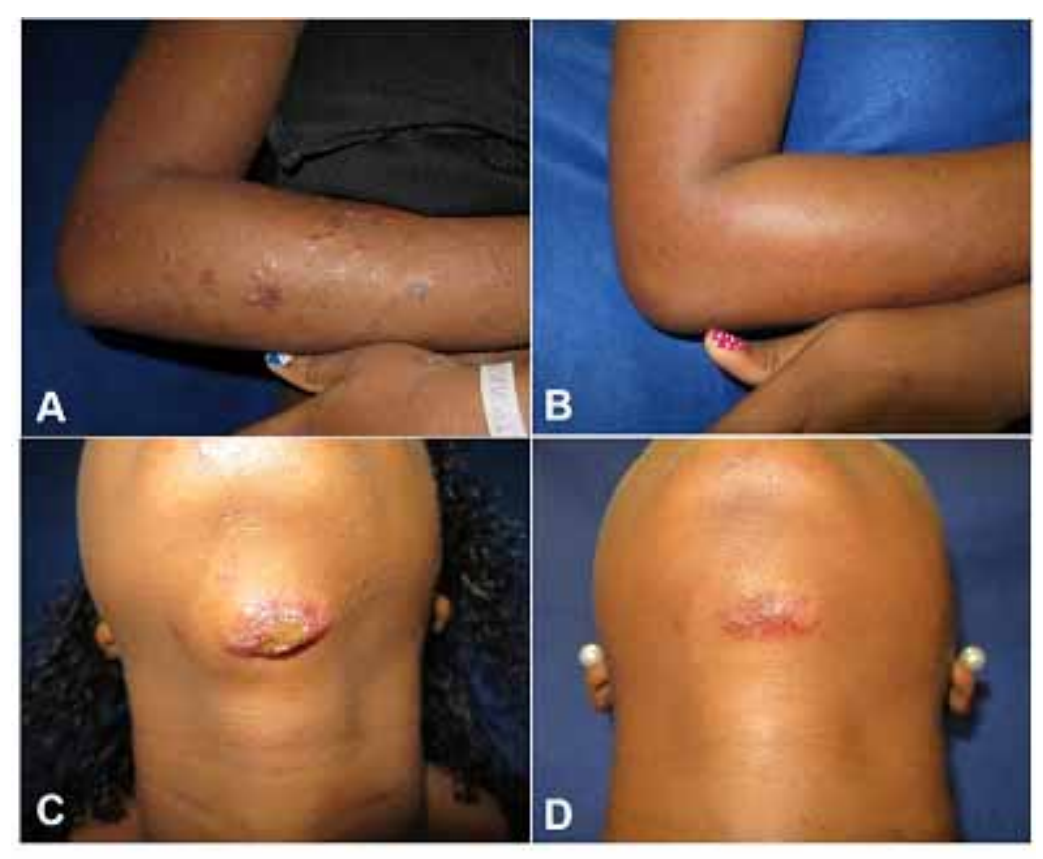

Figura 7: A) lesões do braço antes e B) no $3^{\circ}$ mês do esquema RIPE. C) lesão da região submandibular antes e $D$ ) no $3^{\circ}$ mês do esquema RIPE.

alguns fatores como a exposição prévia ao bacilo, estado imunológico do hospedeiro, a via de infecção de e disseminação, podendo ser hematogênica, linfática ou por solução de continuidade. As tubercúlides consistem em lesões de hipersensibilidade, geralmente não habitadas, que ocorrem devido a presença de um foco sistêmico de tuberculose. No nos- so caso ocorreram três formas clínicas: o escrofuloderma na região submandibular e dois tipos de tubercúlides. Estas consistiram de lesões clinicamente compatíveis com o eritema indurado de Bazin (ElB) nas panturrilhas e lesões disseminadas de tubercúlide pápulo-necrótica (TPN). Na literatura, existem 12 casos descritos da associação do El B 
com a TPN ocorrendo simultaneamente, ${ }^{6,7}$ no entanto não encontramos nenhum relato da ocorrência de três formas concomitantes, que explica a multiplicidade de lesões cutâneas com aspectos clínicos diferentes.

O aspecto clínico variado da TC e a semeIhança com outras doenças dificulta o diagnóstico com base no aspecto morfológico, com isso os métodos diagnósticos complementares são fundamen-

\section{Quadro 1}

Classificação da Tuberculose Cutânea e Tubercúlides

TUBERCULOSES
Cancro Tuberculoso
Tuberculose Verrucosa
Lúpus Vulgar
Escrofuloderma
Tuberculose Orificial
Tuberculose miliar
Tuberculose gomosa
TUBERCÚLIDES
Tubercúlide pápulonecrótica
Eritema Indurado de Bazin
Lichen scrofulosorum

tais e novos exames vêm sendo desenvolvidos para aumentar a acurácia diagnóstica (Tabela 1).4,8

No caso relatado, o exame que auxiliou o diagnóstico foi a biopsia da lesão do braço que evidenciou um processo inflamatório granulomatoso na derme, configurando aspecto em " $\mathrm{V}$ ", com áreas de necrose, compatível com a tubercúlide pápulonecrótica. No entanto, nas tubercúlides não são encontrados bacilos e o diagnóstico é complementado pela positividade do teste de PPD que não pôde ser realizado pela falta do antígeno. Além disso, a biopsia da lesão da perna não contribuiu para investigação e a cultura do exsudato da lesão da região submentoniana foi negativa, bem como os exames para pesquisa da tuberculose pulmonar.

Com isso, o diagnóstico etiológico só foi possível pela utilização de um exame implantando mais recentemente que é o GeneXpert. Trata-se de teste molecular rápido para detecção do $\mathrm{M}$. tuberculosis e da resistência a rifampicina, baseado na metodologia da reação em cadeia de polimerase em tempo real, com resultado em 1:45h. Têm alta sensibilidade e especificidade na tuberculose pulmonar. Exige mínimo treinamento, sendo indicado para uso na rede primária de saúde. Números atuais indicam que sua utilização aumentou em $34 \%$ a detecção de novos casos, em comparação com a baciloscopia. No entanto, estudos indicam menor

\section{Tabela 1}

Métodos Diagnósticos

\begin{tabular}{lcc}
\hline Exames & Tuberculose Pulmonar & Tuberculose cutânea \\
\hline Exames Laboratoriais & & \\
Teste Tuberculínico & $77 \%\left(\mathrm{~S}^{*}\right) ; 59 \%\left(\mathrm{E}^{*}\right)$ & $33-96 \%(\mathrm{~S}) ; 62,5 \%(\mathrm{E})$ \\
Ensaios de liberação de IFN-gama & $90 \%(\mathrm{~S}) ; 93 \%(\mathrm{E})$ & $91,6 \%(\mathrm{~S}) ; 75,8 \%(\mathrm{E})$ \\
Baciloscopia & $40-80 \%(\mathrm{~S}) ; 98 \%(\mathrm{E})$ & $23 \%(\mathrm{~S}) ; 98 \%(\mathrm{E})$ \\
Cultura & $80-85 \%(\mathrm{~S}) ; 98,5 \%(\mathrm{E})$ & $69 \%(\mathrm{~S}) ; 98,4 \%(\mathrm{E})$ \\
PCR (GeneXpert) & $95,7 \%(\mathrm{~S}) ; 99,3 \%(\mathrm{E})$ & $\mathrm{ND}$ \\
Histopatologia & $\mathrm{ND}$ & $\mathrm{ND}$ \\
Exames de I magem & $\mathrm{ND}$ & $\mathrm{ND}$ \\
Raio-X tórax & $\mathrm{ND}$ &
\end{tabular}

${ }^{*} \mathrm{~S}=$ sensibilidade; $\mathrm{E}=$ especificidade; ND = Não descrito 
sensibilidade em amostras de tecido sólido. ${ }^{9,10,11}$ Porém, em nossa paciente, o exsudato da lesão submentoniana se mostrou um material mais adequado para o teste, indicando positividade que, em conjunto com a positividade no escarro, definiu o diagnóstico etiológico.

Concluindo, a alta prevalência da tuberculose em nosso meio, torna possível encontrar formas cutâneas com apresentação atípica e rara, como a do caso relatado que reuniu três variedades clínicas na mesma paciente. Neste contexto, a implantação desta nova tecnologia (GeneXpert) representa um grande avanço pois possibilita o diagnóstico rápido da tuberculose, evitando a progressão e a disseminação da doença por meio do tratamento precoce, como foi demonstrado neste relato.

\section{REFERÊNCIAS}

1. BRASIL. Ministério da Saúde. Série histórica do número de casos novos de tuberculose. Brasil, Regiões e Unidades Federadas de residência por ano diagnóstico (1990 a 2017). Disponível em: http:// portalarquivos2.saude.gov.br/images/pdf/2018/junho/ 19/Casos-novos-tuberculose-1990-2017-base-MAI2018.pdf

2. Ministério da Saúde, Secretaria de Vigilância em Saúde, Departamento de Vigilância das Doenças Transmissíveis. Panorama da tuberculose no Brasil: diagnóstico situacional a partir de indicadores epidemiológicos e operacionais [recurso eletrônico]. Brasília: Ministério da Saúde, 2018.

3. Santos JB, Figueiredo AR, Ferraz CE, Oliveira $M H$, Silva PG, Medeiros VLS. Cutaneous tuberculosis: epidemiologic, etiopathogenic and clinical aspects - Part I. An Bras Dermatol. 2014; 89:219-28.

4. Santos JB, Figueiredo AR, Ferraz CE, Oliveira MH, Silva PG, Medeiros VLS. Cutaneous tuberculosis: epidemiologic, etiopathogenic and clinical aspects - Part II. An Bras Dermatol. 2014; 89:545-55.

5. Azulay, RD, Azulay DR, Azulay-Abulafia L. Dermatologia. 6. ed. Rio de Janeiro: Guanabara Koogan; 2013.

6. Roblin D, Kelly R, Wansbrough-Jones M, Harwood C. Papulonecrotic tuberculide and erythema induratum as presenting manifestations of tuberculosis. Journ of I nfec. 1994; 28: 193-7.

7. Kim GW, Park HJ, Kim HS, Chin HW, Kim SH, Ko HC, et al. Simultaneous Occurrence of Papulonecrotic Tuberculid and Erythema Induratum in a Patient with Pulmonary Tuberculosis. Pediatr Dermatol. 2013;30:256-9.

8. Agrawal M, Bajaj A, Bhatia V, Dutt S. Comparative Study of GeneXpert with ZN Stain and Culture in Samples of Suspected Pulmonary Tuberculosis. J Clin Diagn Res. 2016; 10: 9-12.

9. Iram S, Zeenat A, Hussain S, Tusuf NW, Aslam M. Rapid diagnosis of tuberculosis uxing Xpert MTP/RIF assay Report from a developing country. Pak J Med Sci. 2013; 31: 105-10.

10. Sharma S, Kohli M, Yadav RN, Chaubey J, Bhasin D, Sreenivas $\mathrm{V}$, et al. Evaluating the Diagnostic Accuracy of Xpert MTB/RIF Assay in Pulmonary Tuberculosis. PLOS ONE. 2015; 10:1-9.

11. Hillemann D, Rusch-Gerdes S, Boehme C, Richter E. Rapid Molecular Detection of Extrapulmonary Tuberculosis by the Automated GeneXpert MTB/RIF System. J Clin Microbiol. 2011;49: 1202-05. 